INVESTIGACIÓN/RESEARCH

Recibido: 24/01/2014 ---Aceptado: 23/02/2015 ---Publicado: 15/03/2015

\title{
EVOLUCIÓN DE LA FEMME FATALE EN CAUTIVO DEL DESEO: DE LA TENTACIÓN Y LA HUMILLACIÓN A LA LOCURA Y LA MUERTE
}

\section{Mariona Visa Barbosa: Universitat de Lleida. España. marionavisa@filcat.udl.cat}

\section{RESUMEN (}

En este artículo se analiza la evolución del personaje femenino en la película Cautivo del deseo (Of human boundage, John Cromwell, 1934), interpretada por Bette Davis y Leslie Howard. La mujer protagonista de la historia encarna el papel de una típica femme fatale, que pasa por diferentes estadios a lo largo de la película, los cuales son analizados en detalle en este artículo. Aparece en un principio de forma discreta y positiva para ir poco a poco transformándose en una mujer fría que humilla al protagonista masculino constantemente. Finalmente, como en otros finales de películas del cine negro anterior a la II Guerra Mundial, su personaje es castigado por los guionistas, refugiándola en la locura para llevarla finalmente a la muerte.

Por el contrario, el personaje masculino encarna el arquetipo de un anti-héroe que será transformado positivamente al final de la historia.

En este texto se estudia la evolución de los dos protagonistas de la película y en concreto la forma en que se representa la mujer como femme fatale en las diferentes fases de la historia,. El análisis parte de una metodología narrativa y aplica los postulados de las estructuras antropológicas del imaginario introducidas por Gilbert Durand en los años 60.

\section{PALABRAS CLAVE}

Arquetipo -femme fatale- antihéroe-mujer-género-cine 


\title{
FEMME FATALE'S EVOLUTION IN "OF HUMAN BOUNDAGE": FROM TEMPTATION AND HUMILIATION TO MADNESS AND DEATH
}

\begin{abstract}
This article describes the females's character evolution in the film Of human boundage (John Cromwell, 1934), starring Bette Davis and Leslie Howard. The female main character of the story plays typical femme fatale's role, passing through different stages throughout the film, which are analyzed in detail in this article. At first, the woman appears discreetly and in a positive way, to go slowly transforming into a cold woman who constantly humiliates the male character. Finally, as in other films previous to World War II ending, her character is punished by the writers, sheltering her into madness and finally making her dye. By contrast, the male character embodies the archetype of an anti-hero who will be transformed positively at the end of the story. This paper studies the evolution of the two protagonists of the film and in particular how the women as a femme fatale is represented in the different phases of the film,. The analysis is based in a narrative methodology and applies the principles of the anthropological structures of the imaginary introduced by Gilbert Durand in the 60s.
\end{abstract}

\section{KEY WORDS}

Archetype-femme fatale-antihero - woman-genre-cinema

\section{INTRODUCCIÓN Y OBJETIVOS}

Este artículo realiza un análisis del arquetipo femenino de la femme fatale en Cautivo del deseo (Of human boundage, John Cromwell, 1934).

El cine clásico de Hollywood, comprendido entre los años 30 y 40, es una muestra ejemplar de la presencia y definición del arquetipo masculino y femenino en el inconsciente colectivo. Cómo dice Jung, los arquetipos son instintos que se manifiestan a través de imágenes simbólicas (Jung, 1976). Son formas de pensamiento que se establecieron mucho antes que el hombre desarrollara una conciencia reflexionadora. Estos arquetipos se transmiten a través del inconsciente colectivo, que conserva y transmite la herencia común psicológica de la humanidad. Actualmente, el cine y especialmente los autores más alejados del clasicismo ya no transmiten este inconsciente colectivo, porque las películas son una transferencia de su mundo personal. En cambio, en el clasicismo encontramos este universo en un estado puro. Igualmente, es importante tomar en consideración los arquetipos femeninos que se difunden a través de los medios de comunicación ya que como señalan Piñeiro y Costa (2003) "las mujeres se encuentran con esquemas culturales que propiciarán desde la etapa de socialización primaria, unas expectativas en función de su género que determinarán tanto la posición dentro de la sociedad como la conducta que se va a tomar respecto a ella." 
Esta película narra la historia de Philip Carey (Leslie Howard), un joven con un defecto de malformación en el pie que le imposibilita andar con normalidad. Philip llega a Londres para estudiar medicina después de una temporada en Paris, donde ha intentado desarrollar una carrera, sin éxito, como pintor. En Londres se enamora de la camarera Mildred Rogers (Bette Davis), que no le corresponde, rechazando su proposición de matrimonio. Aún así, Philip la ayudará una vez ella es abandonada, embarazada, por su marido. A partir de este momento Mildred estará siempre presente en la vida de Philip, impidiendo que él desarrolle una carrera profesional y sentimental. Finalmente, Mildred muere y es entonces cuando Philip puede empezar a rehacer su vida.

La película es una adaptación de la novela de Somerset Maugham Servidumbre humana, escrita en 1898. El título original de la novela (Of human boundage) es el mismo que el de la película americana, a pesar de que en la versión española el título es mucho más explícito en cuanto a la temática, Cautivo del deseo.

En este artículo se analizan las características básicas de los principales personajes masculinos y femeninos de la película, así como su evolución, con el objetivo de analizar la presencia de los arquetipos clásicos de héroe solar y de la femme fatale. En concreto, a través de la transformación del personaje interpretado por Bette Davis se ejemplifican los diferentes estadios por los que transita el prototipo de mujer diurna desligados de los signos del tiempo y sin pretensiones maternales ni familiares.

\section{METODOLOGÍA}

La metodología utilizada para estudiar estos personajes parte de las clasificaciones que Gilbert Durand realizó en su libro Las estructuras antropológicas de lo imaginario, en el que estudió las motivaciones simbólicas y aportó una clasificación de los grandes símbolos de la imaginación. Hasta el momento de la publicación del libro, en 1960, había un gran confusión en estos temas ya que las clasificaciones se habían hecho bajo categorías muy diversas como el psicoanálisis, la historia de la religión o la antropología. Durand unifica estos símbolos en dos Regímenes, que son los que enmarcan el esquema general que seguiré para analizar la película. El Régimen Diurno del imaginario "está pensado contra el semantismo de las tinieblas, de la animalidad y de la caída, es decir, contra Cronos, el tiempo inmortal" (Durand,1981, p.77). En este régimen encontramos símbolos como el cetro, la espada y las armas cortantes, el sol y los esquemas ascensionales: las escaleras, las aves diurnas, la lanza o el héroe sauróctono. En cambio el Régimen Nocturno acoge aquellos símbolos que toman en consideración nuestra 
condición mortal: la feminidad benéfica, la madre nutriente, la oscuridad acogedora o el refugio íntimo y tranquilo. "El antídoto del tiempo ya no se seguirá buscando al nivel sobrehumano de la trascendencia y de la pureza de las esencias, sino al de la tranquilizante y cálida intimidad de la sustancia o en las constantes rítmicas que acompasan fenómenos y accidentes." (Durand, 1981, p. 184).

\section{RESULTADOS}

\subsection{LA RENUNCIA A LA HEROICIDAD DEL PERSONAJE MASCULINO}

Tanto en la novela como en la película el protagonista absoluto es el personaje masculino, Philip Carey. De hecho, la novela empieza mucho antes del punto de partida de la película, ya que nos explica la infancia del personaje, obligado a vivir con su tío después de quedarse huérfano.

Teniendo en cuenta las clasificaciones establecidas por Gilbert Durand, Philip es el ejemplo clarísimo de antihéroe. Al menos, respecto del héroe que hasta entonces nos había representado el cine americano: un héroe solar en constante movimiento, siempre preparado para emprender gestas heroicas. Philip está condenado a la inmovilidad por culpa de su defecto físico. La película se inicia haciendo alusión a esta limitación, se define al personaje a partir de esta característica. De hecho, los primeros minutos del filme sirven para mostrarnos la incompetencia de Philip, de manera que el espectador tienda a sentir compasión por él.

Aparte de su cojera, la primera conversación también nos demuestra que es un fracasado como artista. Su profesor de pintura le aconseja que "haga algo con su vida", puesto que pintando cuadros "sólo conseguirá ser un mediocre". Este "haga algo con su vida", que se transformará en el objetivo del desorientado personaje durante toda la historia, demuestra como, alejado de la heroicidad solar, Philip Carey es un ser inmóvil que no se mueve físicamente, y que tampoco sabe qué rumbo dar a su vida. "Podría decirse que la toma de consideración del cuerpo es el síntoma del cambio de régimen del imaginario". (Durand, 1981, p.192).

En el libro de Somerset Maugham hay un párrafo en el que Philip reflexiona sobre su estado: "El dominio de sí mismo podía ser tan ardiente y tan activo cuanto mayor es el abandono de las pasiones y creía que la vida interior podía ser múltiple y variada, rica en experiencias, como la vida de los que conquistan reinos y exploran tierras desconocidas" (Maugham, 1945, p.438). En esta reflexión, Philip deja muy clara su renuncia a la heroicidad.

Nos encontramos por lo tanto, ante un protagonista perdedor, que no sabe qué hacer con su vida. Podría ser un hombre ideal para una heroína nocturna y maternal. Pero evidentemente no es así. Philip Carey será cautivado por los encantos de una femme fatale, diurna y sin escrúpulos.

\subsection{LA PRESENTACIÓN DE LA FEMME FATALE: UNA MUJER DESLIGADA DE LOS SIGNOS DEL TIEMPO}


La femme fatale de esta historia es interpretada por Bette Davis, actriz reconocida en esta materia en filmes como Jezabel (Jezabel, William Wyler, 1938), Amarga Victoria (Dark Victory, Edmund Goulding, 1939), La carta (The letter, William Wyler, 1940) o La loba (The Little Foxes, William Wyler, 1941).

El personaje de Mildred Rogers encarna la feminidad destructora en todos los sentidos, no tiene matices positivos. Físicamente, es alta y delgada, sin ninguna curva voluptuosa. La primera vez que Philip la ve en el bar prácticamente ni se da cuenta de su presencia. Visualmente, la imagen también los separa: él esta sentado y ella de pie; él aparece de cara, ella de espaldas; él con pose seria y e ella riéndose. Un juego de oposiciones que poco hace prever la adicción que Mildred despertará en Philip. Nada los une, e incluso lo primero que Philip verbaliza sobre su aspecto es que es anémica. Creo interesante incluir la definición que hace Somerset Maugham de este momento en el libro:

"A menudo iban a tomar el té en un local de Parliament Street, pues Dunsford admiraba a una de las camareras. A Philip le parecía muy poco atrayente: era alta y delgada, con caderas estrechas y un pecho de niña" (...) "Estaba muy anémica; tenía los labios pálidos, la delicada piel de un tinte verdoso, sin sombra de rosa ni siquiera en las mejillas; los dientes blanquísimos". (Maugham, 1945, p.277).

Cómo vemos, sus atributos no son los propios de la mujer maternal. Incluso si tenemos en cuenta los estudios del francés Frédéric Monnneyron (Monneyron, 2006) su vestuario es el típico del régimen diurno: vestido azul con escote cuadrado. Según este autor, las formas geométricas, la verticalidad y los tejidos lujosos pertenecen al imaginario diurno, mientras que los motivos florales, las incrustaciones, la lana y el algodón formarían parte del imaginario nocturno.

Las figuras cerradas cuadradas o rectangulares hacen hincapié simbólicamente en los temas de la defensa de la integridad interior. El recinto cuadrado es el de la ciudad, es la fortaleza, la ciudadela. El espacio circular es más bien del jardín, del fruto, del huevo o del vientre, y desplaza el acento simbólico a las voluptuosidades secretas de la intimidad" (Durand, 1981, p.236).

Bette Davis tiene poco protagonismo en la película, al igual que en el libro. Aparece y desaparece en momentos imprevisibles, y nunca sabemos lo que piensa al respecto de nada. No la oímos nunca en conversaciones con amigas o con personajes confidentes, y cuando habla con Philip sus palabras están llenas de indecisiones. "¿Por qué no?", "Me da lo mismo", "Si lo desea", "A mí me es indiferente", "Si me acuerdo.." ...

Su poder sobre Philip no nace a partir de la seducción, ni de explotar la fuerza de la mirada. Mildred es ajena a todo aquello humano, a cualquier vínculo, y le interesan mucho más las aventuras que pueda vivir rodeada de personajes heroicos y atrevidos que no la plácida y tranquila seguridad que le ofrece Philip. Su cojera le es indiferente en un principio, aunqueo no le gusta que sea un hombre sin ningún objetivo y sin ninguna ganancia económica. De hecho, uno de los otros pretendientes de Mildred le dice a Philip "Es usted demasiado artista". 
A pesar de este poco interés por parte de ella, Philip empieza a festejarla y a proponerle citas. Cada vez está más enamorado.

Mildred, en cambio, como femme fatale diurna no está sujeta a los dictados del tiempo, siempre llega tarde o se espera en el lugar equivocado. En la primera cita, quedan bajo el reloj de la estación, en el andén de segunda clase. Philip la espera durante mucho rato, y al final se encuentran por casualidad, ya que resulta que ella estaba esperándolo en el andén de primera clase. Lo único amable que le dice, durante tres veces a lo largo de la película es: "Es usted un caballero en todos los sentidos". Pero parece pronunciar esta frase más como un insulto que como un reconocimiento a los buenos modales de Philipp.

En otra de sus citas, cuando Philip le propone matrimonio, ella rehúsa alegando que justamente quería anunciarle que ya se había comprometido y que se casará con otro hombre que tiene más dinero y más buena posición social. Así, Mildred había actuado hasta este momento sin tener en cuenta a Philip. Se citaba con él mientras planeaba casarse con otro. Y cuando lo explica, no parece tener el menor remordimiento o vergüenza. Así, este personaje femenino, al igual que la mayoría de femmes fatales es como un nuevo retrato del mito hesíodico Pandora. Según Hesíodo, Pandora es la primera mujer, ofrecida como regalo a los hombres. Cada Dios le dio una calidad y así recibió la gracia, la belleza, la habilidad manual, la persuasión... Pero Hermes le dio también la mentira. Cómo dice Núria Bou:

Pandora es sensual y peligrosa, inteligente y mentirosa, arquetipo de la feminidad dual, ambigua y temeraria, y seduce y destroza a los hombres. Figura siempre atractiva para la imaginación creadora - plástica, literaria o musical -, Pandora se esconde bajo nombres tan diversos como Carmen, Salomé o Lulú, pero es en la oscuridad de las salas cinematográficas dónde encontramos su fijación cinética". (Bou; 2004, p. 26).

En este caso nuestra Pandora particular es la encarnada por Bette Davis.

A partir de esta escena, ella desaparece por un tiempo. Philip incluso intenta rehacer su vida, pero es incapaz de olvidarla. La femme fatal le ha inoculado el veneno y él ya no podrá deshacerse. Igualmente, ella no tardará muchas escenas en volver a aparecer. Necesita un hogar y dinero porque su marido la ha abandonado, embarazada. Philip ve una oportunidad para reconquistarla y se vuelca en proporcionarle todo lo que ella puede necesitar. Rompe la relación que había empezado a establecer con otra chica y destina todo el poco dinero que tiene para que no le falte de nada a Mildred. En el libro hay un párrafo que ilustra perfectamente el hecho de porque abandona a la otra sin pensárselo y vuelve con Mildred: “(...) siempre es más importante amar que ser amado, y toda su alma tendía hacia la otra (Mildred). Preferiría estar diez minutos con aquella (Mildred) que toda una tarde con ésta (Nora, su nueva novia), y un beso de aquellos labios fríos lo estimaba mucho más que todo lo que Nora pudiera darle". (Maugham, 1945, p. 348).

En esta parte de la historia también volvemos a tener un ejemplo de la diurnidad del personaje de Mildred, desatada de cualquier símbolo que la temporalice: a pesar de su embarazo no demuestra ningún espíritu maternal. Prácticamente todo queda en fuera de campo (a excepción de un brevísimo plano de la cuna) y rápidamente se deshace del hijo, 
dándolo a otro que lo cuide. Cómo dice Jacques Siclier, aludiendo a la femme fatale de Que el cielo la juzgue (Leave her to heaven, John M. Stahl, 1945), "encontramos el mismo rechazo de la maternidad y el aborto provocado propio de todas las bestias malfactoras del estilo de Barbara Stanwyck" (Siclier, 1956, p.88).

Rápidamente desprendida del hijo, Mildred pide a Philip que la lleve a cenar, que la divierta. Los asuntos del hogar la han aburrido enormemente y sólo ansia poder volver a divertirse saliendo de fiesta y conociendo a gente. Para satisfacerla él invita a un amigo suyo que le ayude a distraerla. En esta escena, Philip asiste humillado a la atracción que se despierta entre los dos personajes. La única cosa que podrá hacer, tal y cómo dice su amigo es : "pagar la cuenta" de la cena. Desesperado, cuando el día siguiente se confirman sus sospechas y Mildred afirma estar enamorada de su amigo, el personaje no sabe qué hacer. Es entonces cuando por primera y única vez en toda la película, Philip mira directamente a cámara, aunque un breve instante, para no romper las normas de transparencia del cine clásico. Parece como si nos pidiese consejo, como si el espectador pudiera ofrecerle una solución. Es un momento de reflexión, que dará sus frutos porque es justo a partir de esta escena cuando el personaje, a pesar de la ayuda que siempre le proporcionará, empieza a no querer a Mildred.

\subsection{LA DEGRADACIÓN DE LA FEMME FATALE: EL REFUGIO EN LA LOCURA}

En el párrafo anterior se ha descrito la segunda vez en que el personaje era requerido por la femme fatale, pero no será la última. Después de finalizada la aventura de Mildred con el amigo de Philip, ésta se queda sola de nuevo, con el agravante de que empieza a sufrir problemas de salud. En esta tercera vez en que Mildred aparece en la vida de Philip, ella, por motivos físicos, es incapaz de ir a buscarlo, pero pide a alguien que le haga llegar su dirección. Veremos como cada vez su fuerza es menor y yo no se presenta físicamente ante Philip sino que lo hace a través de un mensajero. Es una debilitación progresiva del personaje. Su hijo ha muerto, está sola y demacrada, enferma. Mildred se echa en sus brazos, pero él simplemente quiere ofrecerle ayuda como médico. Le arregla una casa y le aconseja cuál es el mejor modo de vida. Aquí Philip se comporta como una auténtica mujer del hogar, mientras que Mildred es incapaz de tener la casa ordenada. "La casa es siempre la imagen de la intimidad descansada, (...) el "asiento" definitivo de la iluminación interior " (DURAND; 1981:232), dice Durand, que al igual que Bachelard identifica la casa con la feminidad. Pero esta idea del hogar no tiene nada que ver con la femme fatale propia de esta película, como tampoco la tenían las femme fatales del film noir como la mujer ociosa de Perversidad (Scarlett Streeet, Fritz Lang, 1945), que tiene la casa completamente desordenada durante toda la película.

En estos momentos Mildred coquetea con él, mostrándose dispuesta a entregarse a él. Pero Philip ya no quiere tener ninguna relación sentimental con ella, y en una conversación incluso llega a decirle: "Me das asco Mildred". Ella no lo puede creer. Cuando oye estas palabras, los ojos le salen de las órbitas, y se enfurece. Durante toda la película, su mirada 
siempre está perdida, nunca mira directamente a los ojos de Philip, no utiliza este recurso para cautivarlo. De hecho, como hemos señalado, en la primera escena ni se miran. Y en esta vez, cuando queda patente que Philip no la quiere, ella no sabe dónde mirar, los ojos locos buscan alguna solución recorriendo rápidamente todos los rincones. En este momento Mildred pierde los papeles. Es una situación que recuerda a la última escena de Lo que el viento se llevó (Gone with the wind, Victor Fleming, 1939) cuando Escarlata es abandonada por Rhett Butler. Jaques Siclier apunta que Escarlata es arrinconada con desprecio por el protagonista masculinor, y que esta dama por primera vez rechazada no tiene más alternativa que la locura, que convertirse, con los años, en la desequilibrada Blanche Dubois de Un tranvía llamado deseo ( A Streetcar named desire, Elia Kazan, 1951). Esta sentencia es discutible si tomamos como referencia otras películas, pero en el caso de la Bette Davis de Cautivo del deseo, la mujer queda también totalmente anulada a partir de este momento. Un primer instante de locura y, a partir de este momento, también la degradación del personaje a causa de una enfermedad. Cada vez aparecerá menos tiempo en pantalla y su influencia sobre Philip irá desapareciendo. Es cierto que mientras Mildred viva su poder sobre él será muy importante, impidiendo que el personaje masculino se desarrolle con normalidad, pero es a partir del momento en que él verbaliza su desprecio (que no quiere decir que lo sienta) cuando la narración toma un cariz distinto.

Mildred, en la impulsividad propia de la desesperación, comete en esta escena una última actuación para destruir al personaje. Empieza a insultarle de la forma que más daño le puede hacer a Philip "Maldito cojo", "Tullido ",... Le destroza la casa, le rompe los cuadros y quema el dinero que encuentra. El fuego es invención de la película, ya que no aparece en el libro original, donde Mildred se limita a destrozar el mobiliario. Esta llama, este fuego, es un símbolo de cambio. "Si todo aquello que cambia lentamente se explica por la vida, lo que cambia velozmente se explica por el fuego", como dice Bachelard. "por el fuego todo cambia. Cuando se quiere que todo cambie, se recurre al fuego ". (Bachelard; 1966, p.17).

\subsection{EL FINAL DE LA FEMME FATALE: LA MUERTE COMO CASTIGO}

A partir de aquí, el cambio en Philip es notable. Después de un tiempo, una vez ha recuperado más dinero debido a una herencia, decide operarse el pie. Conoce a una buena chica, hija de un paciente al que ha estado cuidando. Esta nueva chica, joven, conocida en el marco del hogar, es opuesta totalmente a Mildred. "La muchacha sonrió tímidamente, mostrando los dientes blancos y irregulares. Y enrojeció. Estaba bien formada, era alta para su edad, con bellos ojos grises, la frente espaciosa y las mejillas sonrosadas". (Maugham,1945, p.429). Finalmente Philip ha encontrado un rumbo para su vida. La presencia de Mildred todavía le acosa, pero sabemos que, sin su amor, la femme fatale está debilitada.

La tranquilidad, sin embargo, todavía no se ha instalado completamente en la vida de Philip. Un buen día, saliendo de una de las habitaciones del hospital donde trabaja, ve como sacan el cuerpo sin vida de una joven. Él no la ve morir, pero un papel desgarrado en el suelo le informa de que es Mildred. Philip reflexiona unos instantes, pero acto seguido sale a la calle, 
a encontrar a su amada. Progresivamente se había ido alejando del dominio de Mildred, pero la sensación de saberse liberado para siempre de su presencia es nueva para él. "Eres libre", le dice un personaje, refiriéndose a otro tema, pero de especial connotación en este momento.. Fuera del dominio de la femme fatale y solucionado el defecto físico del pie, puede empezar una vida de héroe. Sube en un taxi, y termina la película en movimiento, dirigiéndose a un futuro donde por fin él será el él único que decidirá el rumbo que debe tomar su vida.

Este final es muy diferente de la última parte del libro. En este, Philip no se opera el defecto del pie. En cambio, la película necesita confirmar al final la conversión en héroe de su protagonista. Al menos, termina más próximo al Régimen Diurno de lo que había empezado. La operación le permite ser más activo, caminar con decisión y, en definitiva, lo relaciona con todos los símbolos ascensionales y verticalizantes de la diurnidad. Como dice Durad, "Todos estos símbolos rituales son medios para alcanzar el cielo." (Durand, 1981, p. 120). Son imágenes que nos sirven de contrapunto para la caída y que hacen posible el paso de una realidad estancada a otra dinámica. La segunda diferencia es que en el libro el personaje de Mildred no muere. Acaba degradada, enferma, ejerciendo la prostitución, pero a diferencia de la película, la femme fatale no es penalizada con la muerte.

Una muerte cruel, ya que la heroína fatal que ha dominado al hombre a su voluntad durante todo el filme termina siendo reducida a un papel roto: su historial médico desgarrado y tirado en el suelo. De hecho, a medida que ha estado enferma, ha ido disminuyendo su presencia en pantalla. Su degradación es un proceso en fuera de campo. De este modo, no deja ninguna posibilidad de que el espectador sienta compasión, de que la comprenda, y tampoco ella se puede explicar. No hay opción de ninguna transformación ni evolución del personaje.

\section{DISCUSIÓN}

La heroína de esta película, Bette Davis, es malvada de principio a fin y no aparece ninguna posibilidad de ser salvada. Es malvada como lo eran la mayoría de personajes en el cine previo a la II Guerra Mundial, donde las mujeres que mostraban algún tipo de deseo (de amor o de libertad) eran siempre castigadas, no tenían posibilidad de transformación.

La muerte de Mildred es la muerte de una femme fatale diurna, ya que no se intuye en Mildred ningún indicio de una posible transformación en femme fatale nocturna, consciente de su papel. Ningún instante para la reflexión para ver en ella una feminidad diferente, la que podría salvarla. Mildred desaparece progresivamente en la película y en ningún momento se muestra compasión por ella. Posiblemente, su personaje no tiene redención final 
porque no hemos visto ninguna chispa de amor en su interior. Ha actuado por despecho en todo el filme, sin ningún objetivo claro.

Castigarla con la muerte es sin duda una solución extrema. Lo único que ha hecho Mildred es complicar la vida de Philip, pero de manera involuntaria, no es una heroína maquinadora. Mildred realmente no quiere nada de Philip. Es él quien cae accidentalmente en sus manos, y Mildred lo gobierna porque las circunstancias y él mismo lo permiten, una vez se ha enamorado perdidamente de ella. La historia que cuenta esta película es incluso banal si lo miramos así. Lo que sorprende, a la vez que es el auténtico reflejo del arquetipo femenino de la época, es la negatividad con que Hollywood trata a Mildred. Queda bien claro que en la época no había espacio para una heroína solar que renuncia a los lazos del tiempo.

\section{REFERENCIAS}

Bachelard, G. (1966): Psicoanálisis del fuego, Madrid: Alianza.

Bou, N.; Pérez, X. (2000): El temps de l'heroi. Èpica i masculinitat en el cinema de Hollywood, Barcelona: Piados

Bou, N. (1996): La mirada en el temps. Mite i passió en el cinema de Hollywood., Barcelona: Ed. 62,

Bou N. (2004): Deeses i tombes. Mites femenins en el cinema de Hollywood, Barcelona: Ed. Proa

Durand, G. (1981): Las estructuras antropológicas de lo imaginario,. Madrid: Taurus

Grimal, P. (1997) La mitología griega, Barcelona: Paidós

Jung, C. G. (1976): El hombre y sus símbolos, Barcelona: Luis de Caralt Editor

Maugham, S. (1945): Servidumbre humana, Barcelona: Ed. Lara

Monneyron, F. (2006): 50 respuestas sobre la moda. Barcelona: Gustavo Gili.

Pintor, I. (2001): "Sobre l'imaginari" ; Formats, No 3. Barcelona

Otero, M. T. P., \& Sánchez, C. C. (2003). Representaciones femeninas en la publicidad. Una propuesta de clasificación. Revista de la SEECI, 6(10), 1-13.

Siclier, J. (1956): Le mythe de la femme dans le cinéma americain, Paris: Les Editions du Cerf,

\section{AUTORA}

\section{Mariona Visa Barbosa}

Mariona Visa Barbosa (Lleida, 1979) es doctora en Comunicación Social por la Universitat de Lleida y licenciada en Comunicación Audiovisual por la Universitat 
Pompeu Fabra de Barcelona. Es autora del libro "L'àlbum fotogràfic familiar. Un relat socialitzat de la pròpia vida." (Publicacions UDL, 2013) y co-autora de "Madres en red: Del lavadero a la blogosfera" (Clave Intelectual, 2014). Es profesora investigadora en la Universitat de Lleida, en el Grado de Periodismo y Comunicación Audiovisual, y es miembro del Grupo de Investigación GECIEC (Grup d'Estudis de la Cultura i les Identitats a l'Europa Contemporània). 